\title{
Virtual Lab of Analog AVO Meter to Train Students' Initial Skills before Doing Laboratory Works in Electrical Measurements
}

\author{
Ratna Puspitasari $^{\mathrm{a}, 1}$, Wahyu Hidayat ${ }^{\mathrm{b}, 2}$, Siti Nurul Khotimah ${ }^{\mathrm{c}, 3}$ \\ ${ }^{a}$ Master Program in Physics Teaching, \\ ${ }^{b, c}$ Department of Physics, \\ Faculty of Mathematics and Natural Sciences, Institut Teknologi Bandung \\ Jalan Ganesa 10, Bandung 40132, Indonesia \\ 1'ratna.p@ @students.itb.ac.id, ${ }^{2}$ wahid@ @fi.itb.ac.id, ${ }^{3}$ nurul@ @fi.itb.ac.id
}

\begin{abstract}
This study aims to train students' initial skill in carrying out the measurements with AVO meter. When doing electrical measurements in laboratory, a student is often not aware in using it so that it may not function properly. Therefore, we made a virtual lab of Analog AVO Meter using Macro Visual Basic PowerPoint to solving the problem. First, we organized the materials of analog AVO meter, designed the display media, classified subject matter section on each powerpoint slide, and created their hyperlinks. Second, we created many buttons, such as command button, option button, combo box, and text box then we wrote a computer program on macro visual basic editor to activate the desired command. This virtual lab of AVO meter can train students' initial skill in carrying out the measurements with the meter so that the meter damage can be avoided. This virtual lab also provides skill test about the use of electrical measurement. The measured physical quantities are voltage, electric current, and resistance in series and parallel circuits.
\end{abstract}

Index Terms: Analog AVO Meter, Macro Visual Basic, PowerPoint, Virtual Lab

\section{Introduction}

Virtual lab is a laboratory activity that uses an application program on computer. During the past decade a series of empirical studies revealed the potential of Virtual Manipulative Experimentation (VME) to enhance students' skills, attitudes, and understanding of physics concepts [1]. Besides, using virtual lab allows students to create new intellectual model in education better than the real, and more beautiful than the imagination, reducing the learning time spent in the traditional lab, develop an exploration based on scientific assumptions and processes [2]. The usage of virtual lab media is effective to help provide an overview of the students during the learning process, for example PhET program (Physics Education Technology) has previously been made by University of Colorado. This program simulates some materials support learning in physics, for example simulation on the motion of matter, work and energy, waves, heat and temperature, electrical circuits, quantum phenomena, and others. However, this program has not made a simulation to guide in doing laboratory works in electrical measurements. So, authors took the initiative to create a virtual lab media analog AVO meter using macros visual basic powerpoint for initial skills training before using the appliances for electrical measurements.

Based on the study conducted by Yennita [3], barriers experienced by teachers to implement the required practicum are a special time for preparation before doing laboratory work and the lack of a laboratory worker that can help in Physics lab. On the other hand, one of the barriers faced by students during practical activities is that they are not ready for understanding the practical matter guide before doing laboratory work [4]. The barriers during the laboratory work would have been taken seriously, so that the learning process can be fulfilled as expected. The reasons to select analog AVO meter as a topic are the use of this device requires the initial skills from how to install of equipment in a circuit, how to choose the correct of the measuring limit, how to read the measuring scale, and how to care the analog AVO meter. Thus, the virtual lab program can support to train the initial skills of students before doing experiments in laboratory.

Our previous research has created a learning media of virtual lab analog AVO meter using macros visual basic powerpoint for initial skills training before using the electrical measurements on the circuit two resistors in series [5]. This study was limited to identify the components AVO meter, how to use it according to its function, and read the measuring scale on the circuit of two resistors in series. The purpose of the present study is complementary to previous studies with the addition of content so that the knowledge of how to use the electrical measuring equipment is more comprehensive, such as providing information on safety to use of electrical measuring equipment, how to determine resistance of the resistor with color bracelet, improving the appearance of the resistor component symbol changed to reality components and readings, adding measurements on two resistors in parallel circuit, complementary measurements ranging from the largest scale to avoid a full-scale deflection, and adding facility of skills test using measuring equipment. 


\section{Theory}

AVO meter or Multimeter is equipment used to measure electrical quantities such as voltage, electric current, and resistance in an electronic component or the electrical circuit. There are two types of AVO meters based on how it works, namely, analog AVO meter and digital AVO meters. This study will only discuss an analog AVO meter.

\section{Analog AVO Meter}

Analog AVO meter or so-called analog multimeter displays the quantity of electricity using a moving needle. Analog AVO meter can be used to measure the electric current $(\mathrm{mA})$, voltage (Volt), and resistance $(\mathrm{Ohm})$. The advantage of analog AVO meter is easy and simple in the readings, while its disadvantage is low accuracy.

The working principle of an analog AVO meter is based on the influence of electric current flowing into the circuit AVO meter. The main part of an analog AVO meter is the movement of the coil due to flux change in a permanent magnetic (the permanent-magnet moving coil / PMMC). To know more clearly the working principle of an analog AVO meter, we may refer to the book of Fundamentals Physics Extended Version, Volume 2 [6].

\section{Procedure Using Analog AVO Meter}

Using analog AVO meters is adjusted with the value of electrical quantities to be measured. Installing AVO meter in a circuit must also be complied with the work function of the analog AVO meter. There are several procedures to install AVO meters on a electrical circuit:

\section{a. Measuring DC Voltage}

Set the work function of the meter on the position DC Volt using rotating selector switch. Next, Set the range switch to the correct position. (use the highest range when measuring an unknown voltage). Then, connect correctly the meter to the circuit, and observe proper polarity as shown in Fig. 1.

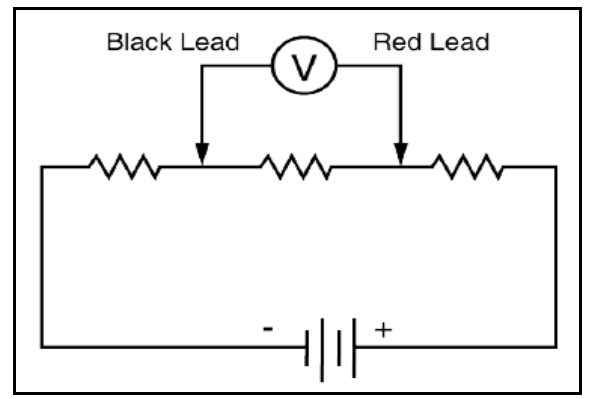

Fig. 1 How to install a DC voltmeter in a circuit (www.masonmonitoring.com)

View meter properly to avoid parallax errors. Locate and read the correct DC volt scale.

b. Measuring DC electric current

Set the work function of meter on the position DC Ampere parts using rotating selector switch. Next, Set the range switch to the correct position (use the highest range when measuring an unknown Ampere). Do not touch the metal probe tips with your fingers since you may get a serious shock. Observe polarity markings when measuring direct current as shown in Fig. 2.

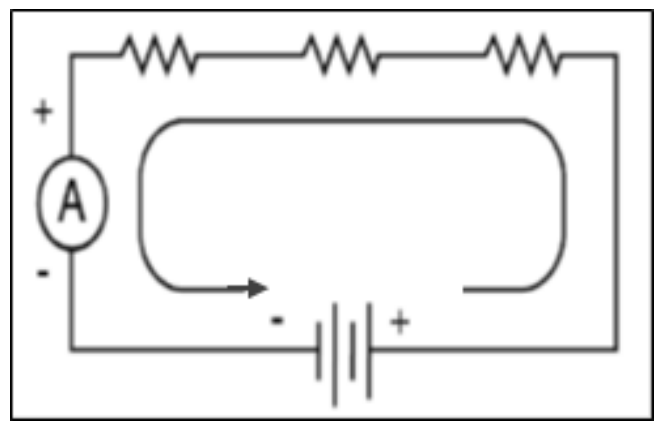

Fig. 2 How to install a DC Ampere meter in a circuit. (www.masonmonitoring.com)

Be sure the current to be measured will not exceed the range setting. Never connect an ammeter in parallel with a circuit. Do not attempt to connect an ammeter to a circuit with the power on (turn the power on after you connect the meter to the circuit). View meter properly to avoid parallax errors. Locate and read the correct DC ampere scale (DCA).

c. Measuring Resistance

Be sure the battery is mounted on the meter before it is used in measuring resistance. Set the work function of meter on the position Ohm parts with rotating selector switch. Zero the meter before you make a measurement. Set the range switch to the correct position (use the highest range when measuring an unknown Resistance). Do not connect an ohmmeter to a circuit with the power on. Do not touch the metal probe tips with your fingers since the resistance of your body may cause inaccurate readings. Connect ohmmeter on the component to the pole test leads can be inverted. Read the results of the measurement designated by the needle on the scale $\mathrm{Ohm}(\Omega)$.

\section{Design and Development}

\section{Procedures of Learning Media}

Figure 3 shows the diagram for making Virtual Lab of Analog AVO Meter. There are 3 main tasks to do: (a) composing materials on analog AVO meter and designing its display, (b) classifying materials on every powerpoint slide, such as: open page, main menu, guidance for using media, components of AVO meter, reading color bracelet of resistors, etc., and (c) making hyperlinks.

\section{Macro Procedures in Visual Basic Editor}

A macro procedure can be done through the Visual Basic Editor window by writing macros codes and run the procedure. Here is the procedure for running the macros program in Visual Basic programming Virtual Lab AVO Meter.

Here is how to activate the CommandButton key to fill some posts in the TextBox and display the hidden images (Fig. 4): 
- $\quad$ Click on the symbol CommandButton control group

- $\quad$ Change the name by clicked the Properties button and fill in the desired name in the Caption column

- Create command on the CommanButton by clicking View Code and writing command in the Visual Basic Editor window.

\begin{tabular}{|c|c|c|}
\hline To arrang & e matter of Analog AVO Meter and desi & me \\
\hline To classifi & ication subject matter each power point $\mathrm{s}$ & slide \\
\hline Slide 1 & Home Page & \\
\hline Slide 2 & Main Menu & \\
\hline Slide 3 & Procedures and Instructions Use of the Media & \\
\hline Slide 4 & The Components of Analog A V $\Omega$ Meter & \\
\hline Slide 5 & The Explanation of Analog A V $\Omega$ Meter & \\
\hline Slide 6 & How to Read the Bracelet Color of Resistor & \\
\hline Slide 7 & How to Read a Measuring Scale & \\
\hline Slide 8 & Safety to Use the Analog $A \cup \Omega$ Meter & \\
\hline Slide 9 & Rule To Use Analog A V $\Omega$ Meter & \\
\hline Slide 10 & Measuring Practice & \\
\hline Slide 11 & Measuring Exercise & \\
\hline To make $\mathrm{I}$ & Hyperlink in media & \\
\hline Home & Slide 1 & \\
\hline About & Slide 2 & \\
\hline & Procedures and Instructions Use of the Med & dia Slide 3 \\
\hline & The Components of Analog A V $\Omega$ Meter $S$ & Slide 4 \\
\hline & The Explanation of Analog A V $\Omega$ Meter & Slide 5 \\
\hline & How to Read the Bracelet Color of Resistor & I Slide 6 \\
\hline & How to Read a Measuring Scale Slide 7 & \\
\hline & Safety to Use the Analog A V $\Omega$ Meter Sli & ide 8 \\
\hline Practice & Slide 9 & \\
\hline & Rule To Use Analog A V $\Omega$ Meter & \\
\hline Exercise & Slide 16 & \\
\hline
\end{tabular}

Fig. 3 Diagram of media creation for Virtual Lab of Analog AVO Meter

Referring Fig. 4, when the CommandButton 4 is pressed, then the TextBox 1 will be filled by the previous posts have been filled with a mark ("..."). As well as a presentation page will be active to bring up the "picture 4" and other pictures will be hidden.

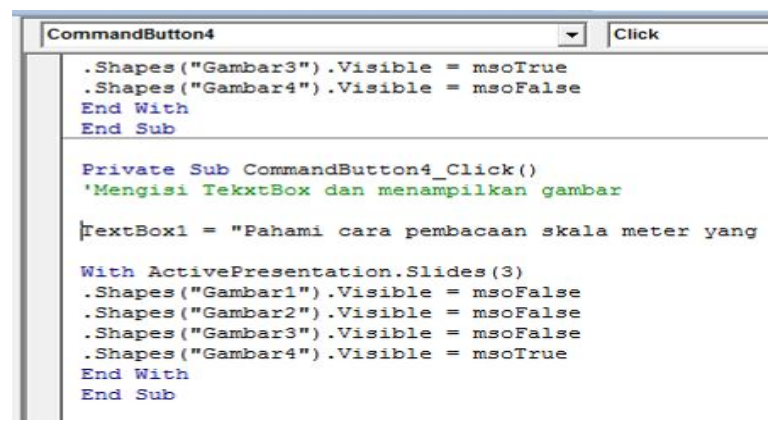

Fig. 4 Command Button Code to fill some posts in the TextBox and to display the hidden image
Enable ComboBox button to select the value of a quantity of electricity (Fig. 5).

- Click on the symbol ComboBox Control group

- Create command on the Tobol ComboBox by clicked View Code and filled orders in the Visual Basic Editor window

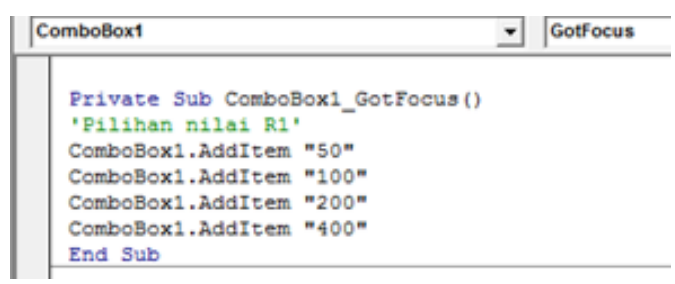

Fig. 5 The command code on the ComboBox to select values of electrical quantities

\section{Results and Discussion}

The virtual lab contains information about how to read color bracelet to determine resistance in a resistor as given in Fig. 6. When a user selects the amount on the value of ComboBox1, the bracelet color to 1, 2, and 3 on the resistor will change according to the values that have been selected. Similarly, when the user selects the value of tolerance on ComboBox 2 , then color of the fourth bracelet will also change according to the value that has been selected.

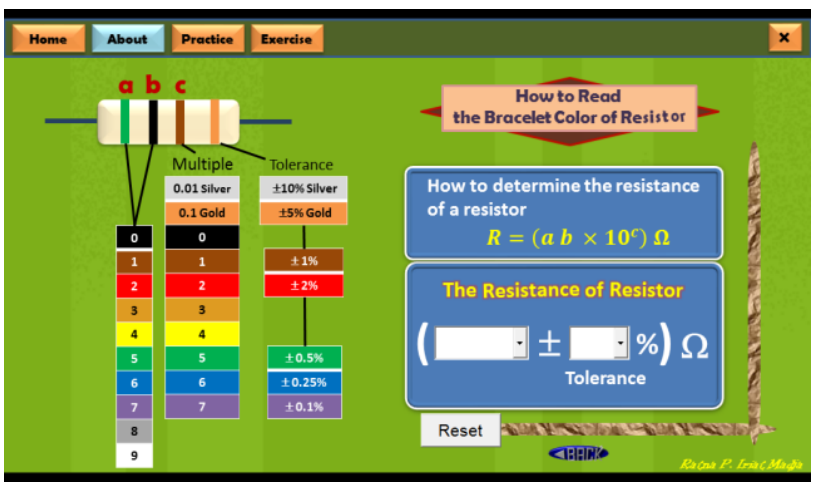

Fig. 6 A display on how to read color bracelet of a resistor

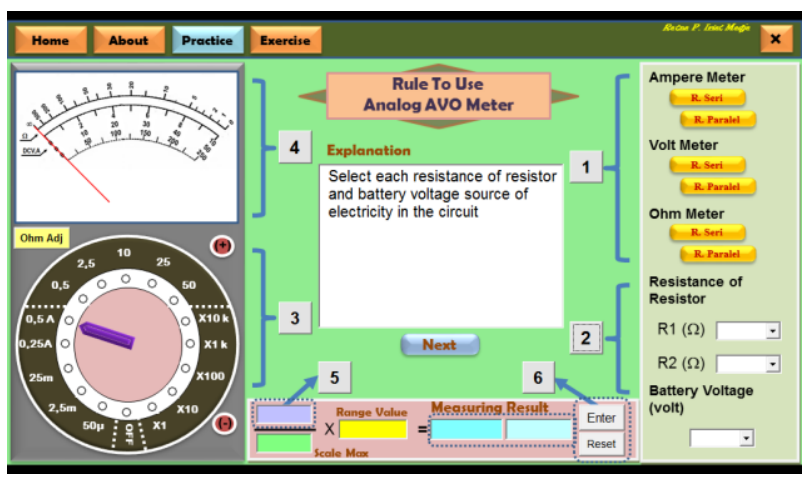

Fig. 7 A display containing AVO meter and the procedure how to use it

Figure 7 displays information about the procedure how to use AVO meter that guides a user in the use of electrical meter to prevent some mistakes during real measurements. The sequence in using the measuring tool is provided with 
the numbers written on the CommandButton. When pressing the CommandButton in accordance with the order number, it will appear the information on the TextBox that has been provided. The user can be trained to recognize the parts of the media before practicing the virtual lab.

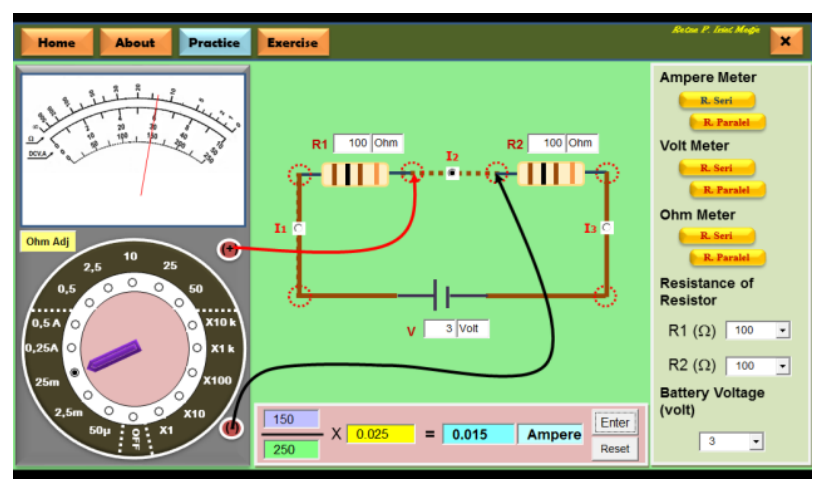

Fig. 8 A display how AVO meter is used in virtual measurement

Figure 8 shows that the virtual lab also contains a simulation how to use AVO meter virtually based on the real measurements. In the practical section, series and parallel circuits are supplied with two resistors so that a user can practice the right measurements such as how to use measuring tools, how to choose a measuring limit scale, as well as how to read a meter scale in accordance with the work function of the AVO meter. In the training section on the use of ammeter on series circuit, the user is guided to choose the largest measuring limit scale to keep the measuring instrument not exceed the maximum limit.

\section{Conclusion}

The Virtual Lab AVO meter has been designed and it was able to be used in training users' initial skills before doing laboratory works in electrical measurements such as voltage, electric current, and resistance.

\section{Acknowledgment}

The authors would like to thank the Faculty of Mathematics and Natural Sciences, Institut Teknologi Bandung for partial support to this work.

\section{References}

[1] Z. C. Zacharia and G. Olympiou. "Physical versus virtual manipulative experimentation in physics learning," Journal of Learning and Instruction, vol. 21, pp. 317-331, 2011

[2] E. Harry and B. Edward. "Making real virtual lab". The Science Education Review, vol. 4, no. 1, pp. 2-11, 2005

[3] Yennita, M. Sukmawati, and Zulirfan, "Hambatan pelaksanaan praktikum IPA fisika yang dihadapi guru SMP negeri di kota Pekanbaru," Jurnal Pendidikan, vol. 3, no. 1, April 2012

[4] Al Imran, "Studi tentang hambatan siswa kelas I Listrik di SMK Negeri 2 Makassar dalam pelaksanaan praktikum Pekerjaan Mekanik Elektro (PME)", Jurnal MEDTEK, vol. 2, no. 1, April 2010

[5] R. Puspitasari, S. N. Khotimah, and W. Hidayat, "Macro Visual Basic PowerPoint sebagai media belajar virtual lab AVO meter analog," Prosiding SKF ITB, pp 276 - 282, 2014

[6] D. Halliday, R. Resnick, and J. Walker, Dasar-Dasar Fisika Versi Diperluas, translation, Jilid 2. Jakarta: Binapura Aksara Publisher, pp. $341-343,2010$ 